\title{
Benign Sebaceous Neoplasm
}

National Cancer Institute

\section{Source}

National Cancer Institute. Benign Sebaceous Neoplasm. NCI Thesaurus. Code C8525.

A benign neoplasm occurring in the sebaceous glands. 